\title{
Suicide contagion, the suicide pact and the effects of suicidal behaviour in therapeutic and family relationships.
}

\author{
(C) 2021 Tony White
}

\begin{abstract}
This article is about suicide and relationships. How suicidal thoughts and behaviours can impact relationships for the suicidal person and those around them. This includes relationships between the suicidal person and other suicidal people as well as the suicidal person and others who are non-suicidal. How the suicidal can impact the other and how the other in turn then impacts the suicidal person back. What effects they have on each other in terms of how they think and feel and then how that effects their transactions with each other. More specifically it examines suicide clusters, suicide pacts, suicidality in the therapeutic relationship and suicidality in family relationships.
\end{abstract}

\section{Introduction}

A huge amount has been written on suicide over the years, within and outside the transactional analysis literature. This article seeks to add to the literature by looking at the role of suicidal thoughts and behaviour in human relationships. Humans are communal beings that naturally tend to form groups, be that families or other types of groups. In these groups people influence and impact each other in how they think, feel and behave. This paper seeks to identify some of the ways suicidal behaviour and talk can impact those others around them in these groups that they have formed.

\section{Key words}

suicide, suicide pact, internet suicide pact, suicide cluster, suicide risk assessment, permission, permission transaction, group think, transference and suicide.

\section{Literature on suicide}

Eric Berne actually wrote very little about suicide, with brief mentions of it only (Berne 1957, 1966, 1972). He made no significant definitive statement about suicide in his writings. Some of the earliest work in the transactional analysis literature on suicide comes from Goulding's (1972) writing on injunctions. In this he described in some depth the Don't be or Don't exist injunction and its relationship to suicidal behaviour. This was the taken up by Holloway (1973) who presented his pivotal work on closing the escape hatch, which was followed by Boyd and Cowles-Boyd (1980) who significantly added to the idea of working with escape hatches in therapy.

Since that time a great deal has been written on various aspects of the topic, such as: Woollams, Brown and Huige (1977); Mellor (1979) with his statement on suicide and dying; Mothersole (1996); and Little (2009). More recently this author (White 2017,2018 ) has written on suicide risk assessment, as well as the relationship between suicide and homicide.

Perhaps the most prominent contribution made to all the literature on suicide was about the no suicide contract and escape hatches. These originally came from the work of Holloway (1973) and Goulding and Goulding (1978). Since that time a huge amount has been written on these and about suicide risk assessment in general. Debate has raged and still does about the validity and usability of no suicide contracts.

\section{Suicide cluster}

A suicide cluster is a group of suicides or suicide attempts that occur in a community that are closer in time than one would normally expect. This is sometimes referred to as the copycat effect with suicidal behaviour. There is significant epidemiological evidence that, when a group of people are exposed to reports of suicide by the media, there is an increase in suicide risk by those who are susceptible to suicide (Stack 1987, 2000; Lawton, Harriss, Simkin et al. 2000; Phillips and Carstensen 1986).

In more recent times, information on suicide spread via the internet has also been seen to increase the risk of suicidal behaviour amongst high-risk individuals (Hagihara, Tarumi and Abe 2007; Rajagopal 2004). Finally these clusters can occur with any age of 
individual but they tend to occur in adolescents and young adults (Robinson, Too, Pirkis and Spittal 2016).

Whilst considered relatively rare they are nevertheless real. Research in Australia over a three-year period from 2010 identified 12 such suicide clusters. This accounted for $5.6 \%$ of all suicides of young people (under 25 years of age) and the clusters ranged in size from 3 to 21 people. The adult clusters accounted for $2.3 \%$ of all suicides of adults and ranged in size from 3 to 31 people (Robinson, Too, Pirkis and Spittal 2016).

Chang, Page and Gunnel (2011) investigated media coverage on specific methods of suicide and subsequent Internet search activity. They found that media coverage of suicide by hydrogen sulphide gassing resulted in online searches increasing 50 times in the month afterwards in Japan, whilst in the United kingdom there was an increase of nine times.

Japan is indeed an interesting case regarding suicide clusters and pacts. Internet suicide related websites have caused much concern there, particularly when it comes to group suicides, Silva (2008) examined this topic and the possible cultural reasons for it, such as the Japanese conception of the afterlife. Moronaga (1988) may also be relevant when he wrote of Japanese 'groupism' which tends to kill individuality: "We Japanese have almost an obsessive desire to conform to other people. This desire to achieve the group norm overrides individual needs and makes Japanese "other-oriented" rather than "selforiented”"'.(p 105).

Regardless of specific cultural differences, suicide clusters demonstrate that people can influence others by their suicidal behaviour, particularly with the young. Several explanations have been presented to explain this, such as imitation, identification and learning. However one that attracts a lot of attention is the idea of contagion. This concept is taken from the study of infectious diseases. The assumption here is that suicidal behaviour can facilitate subsequent suicidal behaviour in others, both directly when there is direct contact between the individual and the person who committed suicide, or indirectly such as via media reports. The cluster can be seen to behave like an epidemic (Haw, Hawton, Niedzwiedz and Platt 2013; Booth 2010).

\section{Suicide pact}

According to Hemphill and Thornley (1969) "A suicide pact is an agreement between two or more persons to end their lives at the same time." ( $p$ 1335). They are quite a rare occurrence in western societies but again Japan usually is seen as having the most suicide pact deaths with around $4 \%$ of all suicides occurring there (GranBoulan, Zivi, and Basquin 1997).
Perhaps Moronaga's (1988) explanation of 'groupism' applies to pacts as well as clusters. Typically the pacts occur in longer term relationships with mostly spouses with a mean average age of 50 years. They tend to be socially isolated, there may be serious health problems, and suicide can be seen as preserving the relationship and not leaving one member behind. I (White 2011) have commented before about what is known as the post suicide fantasy. Magical thinking can occur such that the suicidal person(s) believe they have some kind of consciousness after death, so killing oneself in order to maintain the relationship makes sense. Younger people are also known to engage in suicide pacts, commonly when they have a relationship that is threatened, such as not being allowed to marry (Fishbain, D'Achille, Barsky and Aldrich 1984).

When there is a pact, the suicides tend to be more carefully planned and more lethal methods are chosen, This means that the attempts are more often completed compared to single person suicides. The relationships tend to be intense and socially isolating. There is often dependency by one or both members on each other and sometimes there is relationship asymmetry where one party is the much more dominant one. Indeed a folie à deux has been observed in some suicide pacts (Salih 1981; Noyes, Frye and Hartford 1977).

GranBoulan, Zivi, and Basquin (1997) noted in their research that lover pacts were typical in Japan, spouse pacts in England and friend pacts in Bangalore city, India. This indicates that suicide pacts are usually about relationships and their 'maintenance'. Indeed Hemphill and Thornley (1969) state "Normally the presence of another protects the subject from yielding to the suicidal urge, but in suicide pacts each partner acts on the other, intensifying the urge, so that it is the unit that kills itself, not the partners acting individually, they act as one" (p. 1338).

Regarding transactional analysis, it could be seen that there is an agreement between at least some of the ego states of the two parties. The Parent ego states may agree that a suicide pact is a valid course of action to take. The Adult ego states may agree on the course of action and undertaker the planning to carry out the attempt. The Child ego states experience a relationship that may be intense, socially isolating and both have suicidal drives to some extent.

Both parties have contemporaneous suicidal urges and ideation in the Child ego state. Once this is verbalised in the relationship, both parties realise the other is thinking the same way as them, and a group think type of phenomena begins to occur. The Adult reasoning behind the suicidality is solidified as are the Parent views on the acceptability of suicide as a solution to problems. 
Finally it should be noted that one difficulty with suicide pacts is sometimes one person dies and the other does not. In many countries this would become a police matter, with police assessing how much did the surviving party contribute to the death of the other. For example, did they provide the means for the suicide attempt such as the medication for the over dose and so on. Therapists need to be conversant with local laws on these matters so clients can be correctly informed.

Pursuant to this, in more recent times there has been an increase in what are known as Internet suicide pacts (Crump 2006; Ozawa-de Silva 2008; Bell 2014). People, particularly those who are young, may meet over the internet and begin to discuss suicide, especially through websites that are suicide related. This can lead to suicide pacts of some type developing. If a person does then complete a suicide attempt subsequent police investigations can include reviewing emails of the deceased. Individuals need to be careful what they write so as not to be seen as encouraging the other to make a suicide attempt as this could have serious legal implications. Again therapists need to be aware of the law in this way so clients can be correctly informed.

\section{Group think}

It is now known that the COVID-19 virus can spread from an infected person's mouth or nose in small liquid particles when they cough, sneeze or breathe heavily. If those particles get into the mouth or nose of another person then the virus spreads like a contagion. The permission transaction allows us to explain the contagion effect of suicidality. It provides us with an understanding of the psychological process by which the suicide of one person can 'spread' the suicidality to a high risk other. Thus we have at least one explanation of why suicide clusters occur.

This can lead to what Peck (1990) calls group think. This is where two or more people discuss matters and discover that the other party has similar thoughts and feelings as they do about a particular topic. No dissenting facts or views are presented amongst the various parties. In the case of a suicide pact both people would individually be considering suicide as a possible solution to their problems. When the issue is finally verbalised in the relationship they discover both have the similar ideas and views about suicide.

The main features of group think include:

- There is an increased belief the suicide pact is a right and good goal.

- An illusion of invulnerability that can encourage excessive optimism and risk taking can arise.

- An unquestioned belief in the group's morality and goals arises which can result in the group members ignoring the consequences of their actions.

- Self censorship of deviations in the group's beliefs and goals increases.

- Suppression of dissent by more powerful members in the group may occur.

- Feelings of anonymity arises.

- There can be an increase in discounting self responsibility

As mentioned before, in suicide pacts the relationship tends to be socially isolating, further promoting group think, as dissenting views will not be heard. One could diagram a suicide pact as seen in Figure 1. This can occur in groups from as small as two, to much larger groups with many participants, as long as the group tends to be isolated from any dissenting views.

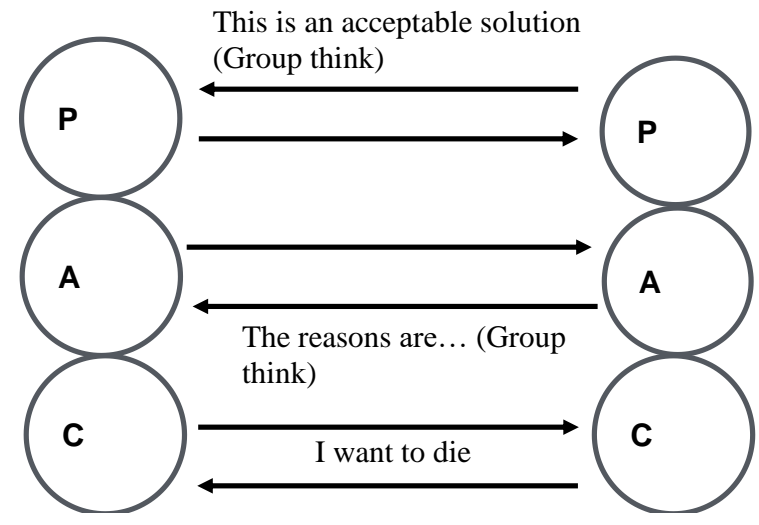

Figure 1: Suicidal Group Think

\section{The contagion effect}

The contagion explanation is often cited in the literature and indicates some confusion whereas the theory of Transactional Analysis can further clarify how the contagion works. In seeking to explain why suicide clusters occur the contagion explanation does not answer this question. It explains what happens, not why it happens. It states that suicidal behaviour can spread like an infectious disease but does not explain the how it is spread from one person to another.

The concept of permission and the permission transaction can provide one explanation of how the 'infection' spreads from one person to another in a suicide cluster. Woollams and Brown (1978) diagram a permission transaction to exist as shown in Figure 2.

Such a permission transaction is then seen to make it easier for the recipient to behave in a way that is congruent with those transactions, in this case to exist and stay alive. Unfortunately it works the other way as well. Permissions can help a person to avoid destructive behaviour but they can also encourage a 


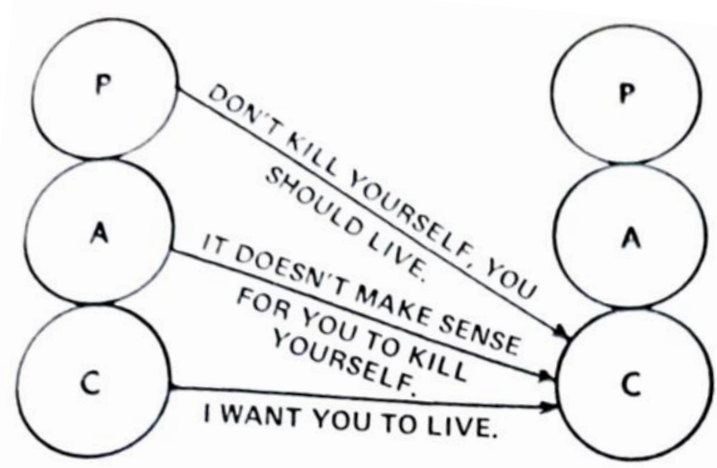

Figure 2: Permission Transaction (Woollams and Brown, 1978, p. 203).

person to behave in self destructive ways. This could explain the contagion effect.

When a person commits suicide and others are informed of that, either directly or indirectly such as via the media, a permission transaction can be seen to occur. The act of suicide by one person is taken as a permission by the other person, that it is OK or possible to do such a thing. See Figure 3 where a person hears of a completed suicide via the media.

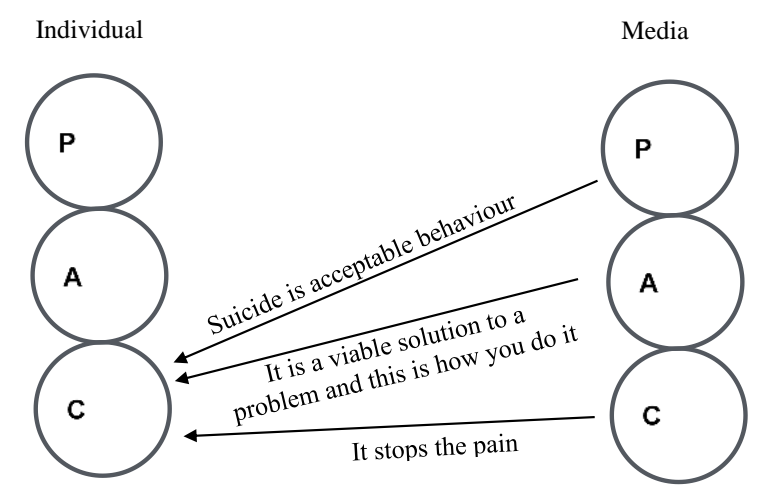

Figure 3: Suicide reported in the media

The individual can be seen to receive a transaction from each of the ego states of the other providing permission for them to make a suicide attempt in the future. If they are prone to suicidal urges then this permission can be quite strong. As White (2018) notes, this is a person who has made the Don't exist decision in early life.

Research shows that other risk factors which can make the permission stronger are being male, adolescent, social isolation, direct involvement with cluster victim and a history of psychiatric hospitalisation (Haw, Hawton, Niedzwiedz and Platt 2013).

\section{The therapeutic relationship}

In workshops on suicide over the years one question the writer often asks participants is: What is your reaction to a person who suicides or makes a serious suicide attempt? Various responses have been collated over the years and commonly include these:

- Anger. The suicidal person is seen as selfish for hurting those left behind.

- Cowardly. It is an act which is seen as the 'easy' way out.

- Feeling sadness and despondency at the waste of a human life.

- Contemplative feelings and one asks the question, Why?

- Feeling frightened and one finds it scary as they seemed so happy.

- $\quad$ Some see it as a courageous act.

- Some experience a sense of guilt and responsibility that they should have done more.

\section{- Some experience a sense of relief}

Finally there is often a philosophical reaction included as well. In this instance one believes that everyone has the right to choose how and when to die. This has been discussed before in the literature by Baba Neal (2017) and Mothersole (1996). They present the idea that people have a choice about suicide. It is their right to choose to die and indeed Mothersole presents the idea of a nonpathological suicide. A person makes a choice to end their life that is not an aspect of their life script and in this sense it can be seen as nonpathological.

One needs to be cautious with such ideas. Whilst debate on such matters of suicide as a freedom of choice maybe acceptable in a scientific journal, it is a different situation in the clinical setting. If a therapist has a suicidal client sitting in front of them one needs to be very cautious in expressing these same philosophical views about suicide to the client. To tell a suicidal client about the concept of nonpathological suicide, that some see suicide philosophically, that all have the freedom to choose if they live or die, needs to be done with great caution. Indeed some would say that communicating such ideas to a suicidal client is definitely contraindicated.

These cautions have been mentioned elsewhere by Allen and Allen (1978). In discussing a therapist's responses to the suicidal client they state, "The last thing they need from the practitioner is permission to 
kill themselves. Unfortunately, in the past, some physicians were trained to say: 'Suicide is one possibility. Now, let's look at alternatives.' This actually gives the patient permission to kill self." (p165). These writers make a very good point and one could diagram the transaction as in Figure 4.

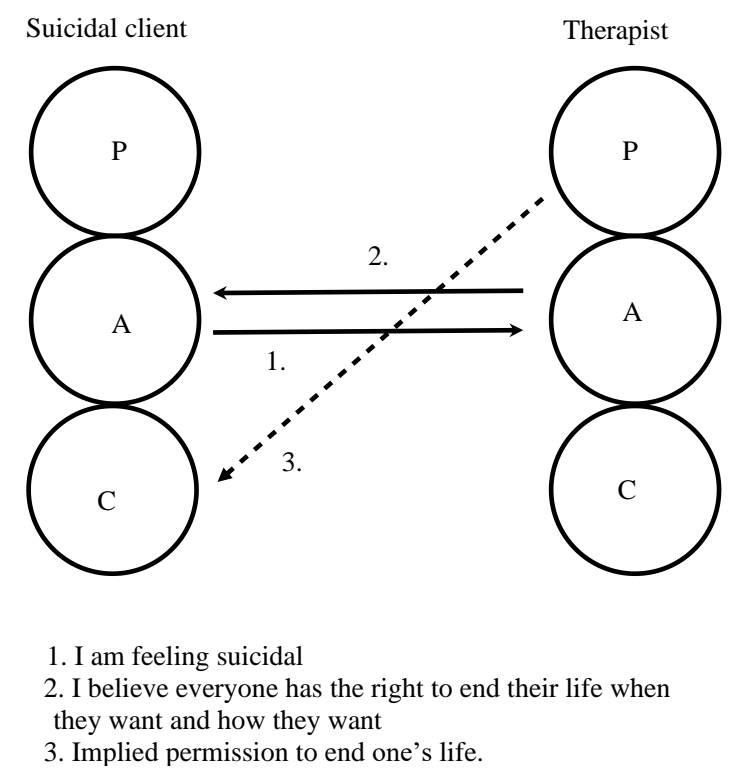

Figure 4: Permission to choose

The client has suicidal urges and the therapist holds the philosophical view of suicide, that people have the right to choose when to die. If the therapist communicates such beliefs to the client this could be seen as the therapist giving the client permission to make a suicide attempt, even if it is an implied permission. Thus we see one way the therapeutic relationship can influence a person's suicidality in an unhealthy way. Compare this to Figure 2 which showed the permission transaction to live, and to very different situations where one demonstrates the permission to stay alive and the other at least implies a permission to make a suicide attempt.

This raises some other interesting questions for scientific journals. The information in these journals is public knowledge. They are available for anyone to read including experienced therapists, inexperienced therapists and people who are not therapists at all. If the editorial boards of these journals publish the philosophical view of suicide we might consider whether it is incumbent upon the editorial board to take action to highlight to potential negative outcomes of these views in the clinical setting.

Of course what also must be mentioned are the ethical considerations about a self-destructive person which all professional organisations consider. Most of these organisations have some kind of ethical principle where the practitioner must provide some kind of protection to such clients.
Barnes (1977) provided a summary of how various TA schools/approaches have used the ideas of escape hatches and the no suicide contract to deal with destructive clients and also how they may apply in a coaching situation. White (2011) has noted current research that shows that between $60 \%$ and $70 \%$ of psychologists and psychiatrists use some kind of no suicide contract or closing of escape hatches. So they are widely used, although there is also a quite sizeable group who are opposed to such contracts for a variety of reasons, including the philosophical view of suicide. Ultimately the practitioner must of course follow ethical principles in the best way they can for the benefit of the client, whatever their views may be.

Another implication is for suicide risk assessment and this was originally presented by White (2011). He states, "First, some are of the view that suicide is everyone's right. Each person has the right to chose when and how to die, for what ever reason they may have.... If a women is suicidal and her husband is of this view, it seems that the marriage may in fact contribute to the level of suicide risk, not reduce it."( $p$. 137). If family members and other people close to the suicidal person have the philosophical view of suicide they can give the permission shown in Figure 4 if they express those views to the individual. If that is the case then the risk of suicide increases and does not decrease, as many risk assessment schedules predict is the effect of having close loved ones around.

\section{Family relationships and suicidality}

Living with a suicidal person is a very emotionally taxing thing to do. It is a very stressful set of circumstances to live under. A parent who is living with an adult child who is suicidal is going to experience significant levels of stress, ongoing, over potentially long periods of time. They wonder each time they return home if they will find the individual dead in the home. Each morning as they awake they wonder whether the individual may be dead in their bedroom. In such circumstances, it is inevitable that the parent's own inner Child ego state sooner or later is going to feel a strong desire for that stress to finish.

Generally the parent will know that the only way for the stress to cease is for the adult child to move away from the home or die. The parent also knows realistically that the suicidal thoughts of the child are not going to subside or finish anytime soon and indeed may persist for a long period of time. In addition at some level the parent also knows that if the individual dies, their own stress about the potential suicide ceases instantly, one hundred percent and forever. This makes it very attractive to the Child ego state.

There are two points to consider about this. First if a parent or other close loved one becomes aware of feeling these things, that can be a source of further 
stress and pain for them. For example, recently a mother told me of an experience with her son, "I was walking behind him down the stairs at our home and all of a sudden I had this thought of shoving him down the stairs in front of me". She raised this with me as it disturbed her and she felt guilty about it. She stated, "How could I, his mother, think such things about my ill son!?" Of course it is a natural feeling for her to have as she was very tired of the stress his prolonged suicidality was having on her. It was only a thought and of course she never acted on that thought. She was reassured of this and allowed an opportunity to express those feelings in the therapeutic setting and the situation was dealt with. In working with close loved ones around the suicidal individual it is necessary to ask about these feelings, then to normalise them and to have the client express them in a way that the client sees fit.

Second, as these feelings can exist in those around the suicidal person, therefore they can be expressed to that person either consciously or unconsciously. In this way those people can support and indeed provide further permission for the person to make a suicide attempt as was shown in Figure 4, but with the family member instead of the therapist. One could say this is a type of suicide pact but in this case the suicidal person can be getting encouragement for suicide by a non-suicidal other. However there is a collusion between them in this way for suicidal behaviour. As stated before most suicide risk assessment schedules will state that having close loved ones around is a protective factor for the suicidal person. However that is not always the case, sometimes they can be an increasing risk factor as just explained here.

\section{Conclusion}

This paper considers suicidal behaviour and how people can impact each other by such behaviour. The literature has long discussed the idea of suicide clusters and suicide contagion and explained what happens with this but does not explain why suicide clusters happen. Through the concept of the permission transaction, transactional analysis can provide one explanation of how the contagion effect of suicide can occur. We need also to consider the processes of group think and how that contributes to suicide pacts.

Finally, we need to review how suicidal behaviour is discussed in the therapeutic relationship, and how family relationships can be impacted upon so they come to include a type of suicide pact in some cases

We need research to provide a more detailed analysis of how one person's thoughts, feelings and behaviours can impact another. More specifically, we need an examination of the ways by which people can have their personality or perception of their own identity become merged or confused with another person. This can apply for all behaviour, which of course can include suicidal behaviour

Tony White is a Teaching \& Supervising Transactional Analyst (Psychotherapy), a psychologist and psychotherapist, and author of numerous articles and several books. He can be contacted on agbw@bigpond.com.

\section{References}

Allen, J. R., \& Allen, B. A. (1978). Guide to

Psychiatry. Medical Examination Publishing Co.

Baba Neal, S. (2017). The impact of a client's suicide. Transactional Analysis Journal, 47(3), 173-185. https://doi.org/10.1177/0362153717711701

Barnes, G. (1977). Transactional Analysis after Eric Berne: Teachings and Practices of Three TA

Schools. Harpers College Press.

https://doi.org/10.1176/ajp.135.10.1263

Bell, J. (2014). Harmful or helpful? The role of the Internet in self-harming and suicidal behaviour in young people. Mental Health Review Journal, 19, 6171. https://doi.org/10.1108/mhri-05-2013-0019

Berne, E. (1957). A Layman's Guide to Psychiatry and Psychoanalysis. Simon and Schuster.

Berne, E. (1966). Principles of Group Treatment. Oxford University Press.

Berne, E. (1972). What Do You Say After You Say Hello? Bantam Books.

Booth, H. (2010). The evolution of epidemic suicide on Guam: Context and contagion. Suicide and LifeThreatening Behaviour, 40(1), 1-13.

Boyd, H. S., \& Cowles-Boyd, L. (1980). Blocking tragic scripts. Transactional Analysis Journal, 10(3), 227-229.

https://doi.org/10.1177/036215378001000310

Chang, S.-S., Page, A., \& Gunnell, D. (2011). Internet searches for a specific suicide method following its high-profile media coverage. American Journal of Psychiatry, 168(8), 855-857.

https://doi.org/10.1176/appi.ajp.2011.11020284

Crump, A. (2006). Suicide in Japan. The Lancet, 367(9517), 1143. https://doi.org/10.1016/s01406736(06)68502-4

Fishbain, D. A., D'achille, L., Barsky, S., \& Aldrich, T. E. (1984). A controlled study of suicide pacts. The Journal of Clinical Psychiatry, 45(4), 154-157.

Goulding, R. (1972). New Directions in Transactional Analysis in Progress in Group and Family Therapy. Brunner/Mazel.

Goulding, R., \& Goulding, M. (1978). The Power is in the Patient. TA Press.

Granboulan, V., Zivi, A., \& Basquin, M. (1997). Double suicide attempt among adolescents. Journal of Adolescent Health, 21(2), 128-130. https://doi.org/10.1016/s1054-139x(97)00003-7 
Hagihara, A., Tarumi, K., \& Abe, T. (2007). Media suicide reports, Internet use and the occurrence of suicides between 1987 and 2005 in Japan. BioMed Central Public Health, 7(1), 321. https://doi.org/10.1186/1471-2458-7-321

Haw, C., Hawton, K., Niedzwiedz, C., \& Platt, S. (2013). Suicide clusters: A review of risk factors and mechanisms. Suicide and Life-Threatening Behaviour, 43(1), 97-108. https://doi.org/10.1111/j.1943-278x.2012.00130.x

Hawton, K., Harriss, L., Appleby, L., Juszczak, E., Simkin, S., McDonnell, R., Amos, T., Kiernan, K., \& Parrott, H. (2000). Effect of death of Diana, Princess of Wales on suicide and deliberate self harm. The British Journal of Psychiatry, 177(5), 463-466. https://doi.org/10.1192/bjp.177.5.463

Hemphill, R. E., \& Thornley, F. I. (1969). Suicide pacts. South African Medical Journal, 1 November, 1335-1338.

Holloway, W. (1973). Closing the escape hatch. The Monograph Series. Midwest Institute for Human Understanding.

Little, R. (2009). Understanding the psychodynamics of suicidal clients: Exploring suicidal and presuicidal states. Transactional Analysis Journal, 39(3), 219228. https://doi.org/10.1177/036215370903900305
Mellor, K. (1979). Suicide: Being Killed, Killing, and Dying. Transactional Analysis Bulletin, 9(3), 3-16. https://doi.org/10.1177/036215377900900307

Moronaga, Y. (1988). Address at the keynote panel. In Bulletin of the Western Pacific Association of Transactional Analysts. WPATA Publications.

Mothersole, G. (1996). Existential realities and Nosuicide contracts. Transactional Analysis Journal, 26(2), 151-159.

https://doi.org/10.1177/036215379602600206

Noyes, R., Frye, S. J., \& Hartford, C. E. (1977). Conjugal suicide pact. The Journal of Nervous and Mental Disease, 165, 72-75.

https://doi.org/10.1097/00005053-197707000-00007

Ozawa-de Silva, C. (2008). Too Lonely to Die Alone: Internet Suicide Pacts and Existential Suffering in Japan. Culture, Medicine, and Psychiatry, 32(4), 516-551. https://doi.org/10.1007/s11013-008-9108-0

Peck, C. (1990). Management and the prevention of war. Australian Psychologist, 25(1), 3-14. https://doi.org/10.1080/00050069008259586 